\title{
УПРАВЛЯЕМЫЙ ХАОС
}

\author{
И. В. Бочарников
}

\section{ТЕРРОРИСТИЧЕСКАЯ ГРУППИРОВКА “ИСЛАМСКОЕ ГОСУДАРСТВО» КАК ЗАКОНОМЕРНОЕ СЛЕДСТВИЕ БЛИЖНЕВОСТОЧНОЙ СТРАТЕГИИ США}

\begin{abstract}
Аннотация. В статье анализируются истоки зарождения террористической группировки «Исламское государство» и факторы, способствовавшие его трансформации в одну из наиболее значимых угроз современной цивилизации. Среди наиболее значимых причин эволюции «Исламского государства» определяется стратегия США по переформатированию ближневосточного политического пространства. В рамках реализации данной стратегии особое значение обрели провоцирование внутриполитических кризисов посредством цветных революций из цикла арабской весны, смещение легитимных правящих режимов, эскалация межэтнической и межконфессиональной розни, поддержка, вооружение, оснащение и финансирование различного рода антиправительственных вооруженных формирований. Методологической основой исследования является системный, структурно-функциональный, сравнительно-политический подходы, методы анализа, синтеза, индукции, дедукции, наблюдения. Данная стратегия осуществляется в отношении и стран Центрально-Азиатского региона. Целью реализации данной стратегии является создание дуги нестабильности на политическом пространстве от Марокко до Китая.Все это в конечном итоге способствовало эскалации террористической угрозы, которой оказались подвержены страны Ближневосточного региона и Центральной Азии.
\end{abstract}

Ключевые слова: геополитика, Россия, мировая политика, внешняя политика США, международные отношения, дипломатия, интересы, государство, безопасность, «цветные революции».

\begin{abstract}
This paper analyzes the origins of a terrorist group called the "Islamic State" and the factors that contributed to its transformation into one of the most significant threats to modern civilization.Numbered among the most significant preconditions for the evolution of the "Islamic State" is the US strategy in the Middle East focused on the reformatting of local political space. A significant part of this strategy involved provoking internal political crises through a cycle of color revolutions of the Arab Spring, the displacement of legitimate regimes, the escalation of ethnic and religious strife, supporting, arming, equipping and financing various types of anti-government armed groups. The methodological basis of the research is a systemic, structural and functional, comparative political approaches, methods of analysis, synthesis, induction, deduction, observation. Similarly, the strategy is carried out in relation to the countries and the Central Asian region. The aim of this strategy is the creation of the arc of instability in the political space from Morocco to China.All of this eventually contributed to the escalation of the terrorist threat, which Middle Eastern and Central Asian countries ended up forced to deal with.
\end{abstract}

Keywords: diplomacy, international relations, U.S. foreign policy, world politics, Russia, geopolitics, interests, state, security, color revolutions.

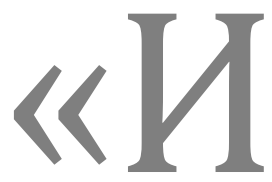

сламское государство» (ранее «Исламское государство Ирака и Леванта» - ИГИЛ) - террористическая организация, действующая на территории Ирака и Сирии. История этой крупнейшей за всю историю человеческой цивилизации исламистской террористической организации началась в 2006 году, когда в оккупированном Ираке объединились 11 радикальных суннитских формирований во главе с местным подразделением «Аль-Каиды» («Каида аль-джихад в Ираке»). Тогда же была принята «конституция» - «Уведомление человечества о рождении Исламского государства». 
До 2013 года группировка называлась «Исламское государство Ирак» (ИГИ). Ее целью был захват суннитской части Ирака и превращение ее в военизированное исламское суннитское государство, после того как из Ирака уйдут силы международной коалиции во главе с США.

В значительной мере эта цель идеологами ИГИЛ была реализована. Как только войска стали выводиться, перманентная террористическая угроза, существовавшая в Ираке в течение всего периода его оккупации, трансформировалась в одну из наиболее значимых глобальных угроз современности.

Хотя причиной эскалации кризиса стал не вывод американских войск и их вооруженных формирований их сателлитов, а напротив вторжение США в Ирак в 2003 году. Именно это стало ключевым фактором, определяющим развитие ситуации, как в Ираке, так и в других странах региона, пораженных метастазами ИГ. О причастности США к его образованию вынужден был признать и американский президент Б. Обама. «ИГ является ответвлением «Аль-Каиды»в Ираке, которое разрослось в результате нашего вторжения, - заявил он в интервью американскому телеканалу Vice News 17 марта 2015 года, И это пример непреднамеренных последствий» [1].

Аналогичной точки зрения придерживается и экс-премьер Великобритании Т. Блэр, заявивший о том, что ИГИЛ является порождением американского вторжения в Ирак в 2003 году [11]. В ходе интервью телеканалу CNN, Блэр извинился за ошибки, допущенные разведкой и за промахи в планировании военной операции в 2003 году.

Тем не менее, процесс формирования современного ИГИЛ был запущен именно тогда, в период вторжения США и Великобритании в Ирак под сотрясание госсекретарем США К. Пауэллом пробирки с неизвестным веществом на заседании Совета Безопасности ООН.

В апреле 2013 года путем слияния двух «филиалов» «Аль-Каиды»в Ираке и Сирии «Исламского государства Ирак» и сирийской «Джебхат ан-Нусра» - была образована группировка под названием «Исламское государство Ирака и Леванта» (ИГИЛ), целью которой стало создание исламского эмирата на территории Ирака, Сирии и Ливана.
10 апреля 2013 года бойцы ИГИЛ присягнули на верность лидеру «Аль-Каиды»А. аз-Завахири. Однако из-за вражды и регулярных столкновений между иракской и сирийской группировками аз-Завахири в ноябре 2013 года принял решение о роспуске ИГИЛ, с тем чтобы «Исламское государство Ирак» и «Джебхат ан-Нусра» действовали независимо друг от друга, одна - в Ираке, а другая - в Сирии. Однако ИГИЛ продолжила действовать на территории обоих государств. И уже к началу марта 2014 года под контролем ИГ находились более трети территорий Ирака и Сирии.

29 июня 2014 года ИГИЛ объявила о создании на захваченных территориях Ирака и Сирии «Исламского халифата», а «халифом» был назначен лидер организации Абу Бакр аль-Багдади. Тогда же было принято решение о переименовании группировки в «Исламское государство» (ИГ).

В середине ноября 2014 года главари ИГ договорились о взаимодействии с экстремистской группировки «Ансар Бейт аль-Макдис», базирующейся в Египте. На ее счету, в частности, нападение на полицейский КПП в секторе Газа, в результате которого погибли 30 египетских солдат. Есть сторонники ИГ и в самом секторе, уже на палестинской территории. Кроме того, верхушка ИГ провела встречи с талибами в Пакистане. Последние сообщения также указывают на то, что «Исламское государство» установило плацдарм в Афганистане. С заявлениями о союзе с ИГ выступили также боевики из группировки «Аль-Муджахиддин» на Аравийском полуострове, в Ливии и Йемене. Так, с 2014 года территории Ливии совершаются теракты боевиками, лояльными ИГ, боевики контролируют провинцию Дерна, некоторые районы Бенгази. В июне 2015 года исламисты захватили город Сирт. Кроме того, ИГ взяла на себя ответственность за теракты, совершенные на территории Йемена и Саудовской Аравии.

На верность Абу Бакру аль-Багдади присягнули также террористические организации из Алжира, Египта, Филиппин, Пакистана. В поддержку халифата выступила и нигерийская «Боко харам».

В январе 2015 года руководство ИГ объявило о создании эмирата Хорасан, в состав которого вошли Афганистан, Пакистан, Индия и 
Бангладеш. Его эмиром был назначен Хафиз Саиид Хан - один из лидеров «Талибан» в Пакистане. ИГ присягнули многие полевые командиры и рядовые боевики движения «Талибан», однако в целом отношения между этими группировками остаются напряженными. В июле 2015 года боевики ИГ опубликовали видеообращение, в котором выразили намерение захватить власть в Палестине и уничтожить Израиль.

Таким образом, метастазы ИГ стремительно распространяются не только в ближневосточном регионе, но и за его пределами, поражая все новые страны и регионы. тельную часть провинций Ракка и Дейр-эз-Зор. Согласно годовому докладу ИГИЛ, попавшему в СМИ, в 2013 году отряды группировки провели в Ираке около 10 тыс. операций, совершили 1 тыс. убийств, заложили и взорвали 4 тыс. устройств, освободили из тюрем несколько сотен экстремистов [14]. Охватившая Ирак волна насилия в 2014 году, по данным ООН, вынудила покинуть свои дома свыше 2 млн. человек. По данным ООН, более 19 тыс. мирных жителей были убиты в Ираке с января 2014 года по август 2015 года, около 30 тыс. получили ранения. На территории же Сирии, по данным Сирийского центра

\section{Карта расползания ИГИЛ от Алжира до Афганистана [7]}

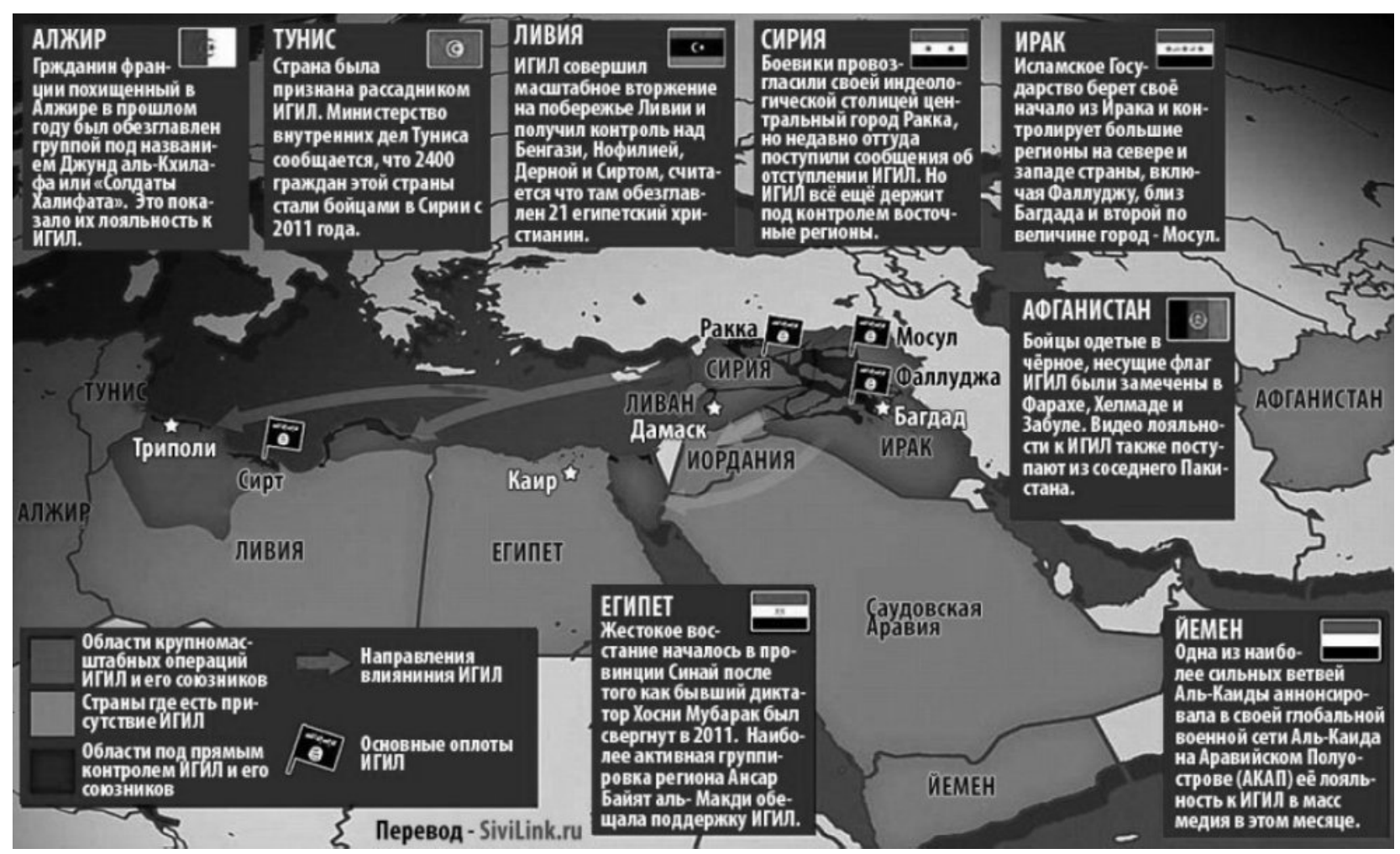

Наибольшей же опасности в сложившейся ситуации подвержены Ирак и Сирия - именно здесь сейчас решаются вопрос или же ИГ будет уничтожено, или данное террористическое образование будет диктовать свои условия, подобно тому, как это делала нацистская Германия до момента нападения на СССР.

В настоящее время в Ираке боевики ИГ контролируют ряд городов в провинциях Анбар, Дияла, Салах-эд-Дин и Найнава, в Сирии - значи- мониторинга за соблюдением прав человека с июня 2014 года по июнь 2015 года боевиками ИГ были убиты более 3 тыс. человек. И это не говоря о терактах ИГ в Ливии, которая может стать третьей базой для этой группировки, и на территории других стран (Саудовской Аравии, Туниса, США, Франции), которые ИГ приписывает своим сторонникам. После терактов в Париже в январе 2015 года стало очевидно, что война перешла границы Ближнего Востока. Опасность 
не только в том, что на родину возвращаются боевики, повоевавшие в Сирии и Ираке, но также в отсутствии профилактики внутри мусульманских общин. В европейских мечетях откровенно пропагандируют джихадистские ценности, и у силовых структур фактически не существует рычагов влияния на ситуацию.

Своего рода визитной карточкой ИГ является распространение видеозаписей с демонстративными казнями, уничтожением культурных памятников человеческой цивилизации, другими актами вандализма.

Все это является не только демонстрацией своей всесильности и безнаказанности, но и средством запугивания, психологического террора с тем, чтобы парализовать волю и способность населения оккупированных ИГ территорий к сопротивлению.

Причинами обретения ИГ значения наиболее острейшей угрозы жизни и безопасности народов и стран региона является ряд факторов.

С одной стороны, это обусловлено наличием у ИГ мощного военного потенциала. Группировка оснащена лучше вооруженные силы Ирака, Сирии или какой-либо иной страны региона. Это стало следствием захвата террористами целых арсеналов с оружием и боеприпасами, заготовленных США для иракских вооруженных сил. Часть этих сил и перешла на сторону ИГ во всеоружии.

Помимо этого арсеналы ИГ значительно пополнили поставки оружия, боеприпасов и техники вооруженным формированиям антисирийской оппозиции со стороны Катара, Саудовской Аравии, США, Великобритании и ряда европейских стран. По всей видимости, поставщики вплоть до настоящего времени так и не разобрались, где «умеренные террористы, а где неумеренные» и продолжают свои поставки.

Резонансным событием в этом плане стало обнародование материалов расследования, каким образом у боевиков ИГ оказались сотни джипов «Toyota Land Cruiser», «Hilux» и др., используемыми боевиками как платформы для орудий и минометов - своего рода «махновские тачанки», но в исполнении ИГ. По данному факту Антитеррористический департамент Минфина США обратился даже с запросом в компанию «Toyota». Но в результате проведенного расследования оказалось, что в 2013 - 2014 годах Госдеп
США поставлял эти джипы «Свободной сирийской армии» в рамках «гуманитарной» помощи.

Не осталось в стороне от этого процесса и правительство Великобритании. Так, еще в 2013 году британская газета The Independent опубликовала материал под названием «Разоблачение: что Запад дал мятежникам Сирии», где говорится, что Великобритания направила оборудования на сумму около 8 млн. фунтов стерлингов, в соответствии с официальными бумагами, с которыми ознакомилась The Independent. Так, «помощь» состояла из пяти транспортных средств с баллистической защитой; 20 комплектов бронежилетов; четырех грузовиков (три 25-тонных и один 20-тонный); шести внедорожников; пяти небронированных пикапов; одной эвакуационной машины и пр.

Поэтому, как отмечает по этому поводу Институт мира и процветания Рона Пола, министерство финансов США должно было направить запрос не в Toyota, а в Государственный департамент США [13].

Немаловажным фактором является и человеческий фактор.

Костяк ИГ составляют боевики, сражавшиеся с американскими войсками в период их пребывания в Ираке и с силами правительства Б. Асада в Сирии. Среди командиров отрядов в ИГ преобладают иракцы, но имеется и большая прослойка саудовских моджахедов.

Достоверных данных о численности группировки нет и быть не может с учетом высокой миграции ее членов. В то же время ряд официальных источников как в России, так и в США определяют возможную численность экстремистов ИГ в 30-40 тыс. человек. По данным же иракских источников, их численность превышает 200 тыс. человек, что, конечно же, является преувеличением [9]. Несмотря на столь широкий разброс в оценках, очевидно, что численность боевиков ИГ, безусловно, велика и налицо тенденция ее роста, в основном за счет наемников из стран, не относящихся к ближневосточному региону. По информации различных источников, в рядах боевиков воюют граждане 80 стран, в том числе Франции, Великобритании, Германии, Марокко, Саудовской Аравии, США, Канады, Российской Федерации и стран СНГ. При этом количество иностранцев в рядах ИГ, по заявлению директора ФСБ России 
А. Бортникова, составляет до $40 \%$ численного состава. Порядка 10 бандформирований состоят из граждан России, Грузии, Украины и государств Центрально-Азиатского региона [15].

Обращает на себя внимание и портрет среднестатистического наемника, воюющего в рядах ИГ. Так, по данным эксперта рабочей группы ОOH по вопросам наемников Е. Карска, в рядах ИГ воюют в основном молодые люди в возрасте 23 года и меньше. При этом речь не идет о безработных, многие члены бандформирований являются вполне обеспеченными и живут в хороших социальных условиях». Все чаще на поездку в Сирию решаются женщины [5].

Это, свидетельствует о том, что для значительной части молодежи участие в террористической деятельности воспринимается как вполне обыденное занятие, к томуже высокооплачиваемое. Все это, конечно же, расширяет социальную базу ИГ и повышает его боевые возможности.

Этому способствует ряд факторов, наиболее значимых из которых, является эффективная информационно-психологическая работа по рекрутированию наемников ИГ в различных странах. Участие в боевых действиях на стороне этой террористической организации окутывается ореолом романтики и героизма, преподносится как борьба за справедливость, за моральнонравственные ценности, в то время как современная цивилизация, особенно западная, все больше склоняется к паранормальности, легализуя однополые браки, наркотики и т.д. Все это эффективно используется вербовщиками ИГ для вовлечения молодежи, в том числе европейской и американской, для вовлечения в ряды данной террористической организации.

Немаловажным фактором усиления ИГ является и финансовая составляющая, определяемая высокими доходами, которые оно получает от криминального бизнеса. Основным источником дохода исламистов является нелегальная торговля нефтью с захваченных месторождений и нефтеперерабатывающих предприятий. В настоящее время под контролем ИГ находится $60 \%$ нефтяных месторождений, расположенных в восточных провинциях Сирии, а также примерно 5-7 месторождений и два НПЗ в Ираке. По данным израильского издания журнала Forbes, ежедневная прибыль от незаконной продажи нефти составляет около \$2 млн. Цена на нефть у ИГ колеблется от $\$ 25$ до $\$ 50$ за баррель, и ежедневно экстремисты реализуют почти 30 тыс. баррелей [6].

Кроме того, боевики получают выкуп за заложников, занимаются рэкетом и грабежом, собирают «исламский налог» (налог за отказ принять ислам суннитского толка). В 2013 году радикалы заработали почти \$63 млн. на выкупах заложников. Порядка $\$ 7,8$ млн. в месяц поступают в виде поборов с местного бизнеса.

Помимо этого ИГ получает денежные средства от частных инвесторов из стран Персидского залива, поддерживающих борьбу с режимом Б. Асада. Наконец, одной из наиболее значимых статей дохода является контрабанда культурных ценностей и исторических артефактов, захваченных террористами на территории Ирака и Сирии [6].

Для мировой общественности шокирующими стали факты уничтожения древнейших памятников человеческой цивилизации в Месопотамии (Ирак) и Пальмире (Сирия). Но ведь очевидно же, что взрывается только то, что не может быть продано; то, что может, - продается через посредников на подпольных аукционах «любителям старины» стран «цивилизованного» мира.

В этом плане, по крайне мере, лицемерным выглядит заявление Госдепартамента США о вознаграждении в \$5 млн. за информацию о финансировании ИГ [3]. С той системой тотальной слежки и шпионажа, утвердившейся в США, «под колпаком» у которой находятся даже главы ведущих европейских государств, выявить скупщиков краденного, при желании вполне возможно.

Но в том и дело, что этого желания, по всей видимости, и нет. Поистине прав был в свое время А. Ришелье, охарактеризовав подобную ситуацию словами: «Нет необходимости видеть зло, если нет желания с ним бороться» [8]. Именно это и демонстрируют США и их союзники [18] как в процессе противодействия ИГ в современных условиях, так и в целом в рамках своей «антитеррористической» операции, начавшейся еще в Афганистане в 2002 году.

Те потуги, которые совершали на протяжении более трех лет американцы и их союзники в рамках борьбы с ИГИЛ, чью деятельность сами 
США заявлениями высших должностных лиц, в том числе президента страны обозначили в качестве наиболее значимой угрозы современной цивилизации, являют собой, по сути дела, имитацию бурной деятельности, граничащей с профанацией.

США одной рукой боролись с ИГ (ИГИЛ), нанося ракетно-бомбовые удары, жертвами которых зачастую являлись лица, не имеющие отношение к этой террористической структуре, другой же - подпитывали, их техникой и вооружением, не осознавая, что, по сути, так называемая вооруженная сирийская оппозиция и ИГ являют собой сообщающиеся сосуды.

При этом самих игиловцев бомбили оченьочень аккуратно, так чтобы не подорвать их боевой потенциал, который должен был быть направлен на свержение Б. Асада - это главная задача, которую поставили американские геостратеги перед собой и своими союзниками. Все остальное - второстепенное, сопутствующее. C ИГ, как считают, американцы можно будет покончить, после того, как они исполнят свою мис- сию - помогут свергнуть неугодный режим, по аналогии с созданными ими ранее Аль-Каидой, Талибаном и иными питомцами: от «контрас» в Никарагуа до карательных батальонов на Донбассе.

В конечном итоге сами США оказались в роли не только спонсоров терроризма, но и его заказчиком. Все это, напоминает события более чем 75-летней давности, происходившие в рамках политики умиротворения нацистов с тем, чтобы они обрушили свой потенциал на сокрушение СССР. Чем это закончилось для Европы - известно. США в ходе Второй мировой войны удалось отсидеться за океаном. На этот раз, по всей видимости, история повторяется. США, инициировав масштабные социально-политические катаклизмы в Центральной Азии и на Ближнем Востоке, надеются вновь «отсидеться за океаном» [17], Европа же уже начинает пожинать плоды «арабской весны»как в виде беженцев из стран победивших революций, так и в виде терактов в Париже в январе и ноябре 2015 года.

\section{Библиография}

1. Барак Обама назвал появление ИГ результатом действий США на Ближнем Востоке http:// webnovosti.info/

2. Бочарников И.В. Борьба с терроризмом: между молотом и наковальней? // Власть. 2004. №12. С. 40.

3. Госдепартамент США объявил о вознаграждении в $\$ 5$ млн за информацию о финансировании ИГ http://tass.ru/mezhdunarodnaya-panorama/2302343

4. Гушер А.И. Геополитические и стратегические аспекты операции Воздушно-космических сил России в Сирии http://nic-pnb.ru/operational-analytics/geopoliticheskie-i-strategicheskie-aspektyoperatsii-vozdushno-kosmicheskih-sil-rossii-v-sirii/

5. ИГИЛ платит вербовщикам до 10 тыс. долларов США http://www.novpressa.ru/news-politika. html?p2_articleid=2239.

6. Израильский Forbes назвал ИГ самой богатой террористической группировкой http://tass. $\mathrm{ru} / \mathrm{mezhdunarodnaya-panorama/1567381}$

7. Карта расползания ИГИл от Алжира до Афганистана http://sivilink ru/igil-ot-alzhira-do-afganistana/

8. Кнехт Р. Ришелье. М.,1997. С.31.

9. Кто воюет в Сирии? http:/politrussia.com/world/kto-voyuet-v-809/

10. Манойло А.В. Закат Рах Americana // Стратегия России. 2015. №11.С. 23-28.

11. Тони Блэр признал, что ИГИЛ возникло из-за вторжения США в Ирак http://pravdanews.info/tonibler-priznal-chto-igil-vozniklo-iz-za-vtorzheniya-ssha-v-irak.html

12. Путин В.В. Руководствоваться не амбициями, а общими интересами //Стратегия России. №11. ноябрь. 2015. 
13. Поставщиками джипов Toyota в Сирию оказались США и Британия http://newsland. com/news/detail/id/1622151/

14. Что такое «Исламское государство» и чем оно опасно? http://muslib.ru/groups/169/journal/12003. html

15. ФСБ: Доля иностранных наемников в ИГ достигает $40 \%$ http://www.rosbalt.ru/ main/2015/10/28/1455543.html

16. Codagnone C., Filippov V. Equity, exit end national identity in a multinational federation: the "multicultural constitutional patriotism" project in Russia. // Journal of ethnic and migration studies. 2000. V. 26. №2. P. 263-288.

17. Манойло А.В. Политические конфликты в международных отношениях и мировой политике. //Мир и Политика. 2013. №2. С. 71-82.

18. Манойло А.В. Глобальная нестабильность на пороге новой большой войны. // Мир и политика. - 2012.-№12. - С. 87-89.

19. Гушер А.И. Вызовы и угрозы безопасности России // Мировая политика. - 2014. - 1. - С. 64 - 75. DOI: 10.7256/2409-8671.2014.1.10748. URL: http://www.e-notabene.ru/wi/article_10748.html

20. Бородинов Е.Н. Анализ крымской внешнеполитической операции // Мировая политика. - 2015. - 1. - С. 81 - 88. DOI: 10.7256/2409-8671.2015.1.12586. URL: http://www.e-notabene.ru/wi/article_12586.html

21. Карякин В.В. Цивилизационная антропология американского экспансионизма: от доктрины Монро к глобальному лидерству // Международные отношения. - 2013. - 4. - C. 487 - 468. DOI: 10.7256/2305-560Х.2013.4.9722.

22. Фельдман П.Я. Геополитический клиентелизм в международных отношениях: стратегия и тактика Запада. // Международные отношения. - 2014. - 2. - C. 189 - 193. DOI: 10.7256/2305-560Х.2014.2.11365.

23. Семченков А.С. Военные угрозы безопасности государств в условиях глобализации // Конфликтология / nota bene. - 2015. - 3. - С. 292 - 304. DOI: 10.7256/2409-8965.2015.3.14334.

24. Гушер А.И. Кризис на Украине: геополитические и геостратегические аспекты // Мировая политика. - 2014. - 4. - C. 79 - 89. DOI: 10.7256/2409-8671.2014.4.11605. URL: http://www.e-notabene. $\mathrm{ru} /$ wi/article_11605.html

25. Саушкин А. Перспективы отмены санкций в отношении России // Международные отношения. - 2015. - 1. - C. 117 - 120. DOI: 10.7256/2305-560X.2015.1.13506.

26. Гушер А.И. Экспертная оценка политико-экономической ситуации в Украине // Международные отношения. - 2014. - 3. - С. 326 - 331. DOI: 10.7256/2305-560X.2014.3.11815.

27. Буневич Д.С. Крымский кризис 2014 года и создание новой архитектуры международных отношений // Конфликтология / nota bene. - 2015. - 2. - C. 133 - 139. DOI: 10.7256/2409-8965.2015.2.14333.

28. А. Э. Галумов Роль публичной дипломатии в формировании позитивного имиджа ЕС в России // Национальная безопасность / nota bene. - 2012. - 4. - С. 77 - 85.

29. Федякин И.В. Мегаполисы как субъекты политики: история и современное состояние // Международные отношения. - 2014. - 1. - C. 88 - 93. DOI: 10.7256/2305-560X.2014.1.10165.

\section{References (transliterated)}

1. Barak Obama nazval poyavlenie IG rezul'tatom deistvii SShA na Blizhnem Vostoke http://webnovosti. info/

2. Bocharnikov I.V. Bor'ba s terrorizmom: mezhdu molotom i nakoval'nei? // Vlast'. 2004. №12. S. 40.

3. Gosdepartament SShA ob"yavil o voznagrazhdenii v $\$ 5 \mathrm{mln}$ za informatsiyu o finansirovanii IG http:// tass.ru/mezhdunarodnaya-panorama/2302343

4. Gusher A.I. Geopoliticheskie i strategicheskie aspekty operatsii Vozdushno-kosmicheskikh sil Rossii v Sirii http://nic-pnb.ru/operational-analytics/geopoliticheskie-i-strategicheskie-aspekty-operatsiivozdushno-kosmicheskih-sil-rossii-v-sirii/ 


\section{Тренды и управление 4(12) • 2015}

5. IGIL platit verbovshchikam do 10 tys. dollarov SShA http://www.novpressa.ru/news-politika. html?p2_articleid=2239.

6. Izrail'skii Forbes nazval IG samoi bogatoi terroristicheskoi gruppirovkoi http://tass. $\mathrm{ru} /$ mezhdunarodnaya-panorama/1567381

7. Karta raspolzaniya IGIL ot Alzhira do Afganistana http://sivilink.ru/igil-ot-alzhira-do-afganistana/

8. Knekht R. Rishel'e. M.,1997. S.31.

9. Kto voyuet $v$ Sirii? http:/politrussia.com/world/kto-voyuet-v-809/

10. Manoilo A.V. Zakat Pax Americana // Strategiya Rossii. 2015. №11.S. 23-28.

11. Toni Bler priznal, chto IGIL vozniklo iz-za vtorzheniya SShA v Irak http://pravdanews.info/toni-blerpriznal-chto-igil-vozniklo-iz-za-vtorzheniya-ssha-v-irak.html

12. Putin V.V. Rukovodstvovat'sya ne ambitsiyami, a obshchimi interesami //Strategiya Rossii. №11. noyabr'. 2015.

13. Postavshchikami dzhipov Toyota v Siriyu okazalis' SShA i Britaniya http://newsland. com/news/detail/id/1622151/

14. Chto takoe «Islamskoe gosudarstvo» i chem ono opasno? http://muslib.ru/groups/169/journal/12003. html

15. FSB: Dolya inostrannykh naemnikov v IG dostigaet 40\% http://www.rosbalt.ru/main/2015/10/28/1455543. html

16. Codagnone S., Filippov V. Equity, exit end national identity in a multinational federation: the "multicultural constitutional patriotism" project in Russia. // Journal of ethnic and migration studies. 2000. V. 26. №2. P. 263-288.

17. Manoilo A.V. Politicheskie konflikty v mezhdunarodnykh otnosheniyakh i mirovoi politike. //Mir i Politika. 2013. №2. S. 71-82.

18. Manoilo A.V. Global'naya nestabil'nost' na poroge novoi bol'shoi voiny. // Mir i politika. - 2012.-№12. - S. 87-89.

19. Gusher A.I. Vyzovy i ugrozy bezopasnosti Rossii // Mirovaya politika. - 2014. - 1. - C. 64 - 75. DOI: 10.7256/2409-8671.2014.1.10748. URL: http://www.e-notabene.ru/wi/article_10748.html

20. Borodinov E.N. Analiz krymskoi vneshnepoliticheskoi operatsii // Mirovaya politika. - 2015. - 1. - C. 81 - 88. DOI: 10.7256/2409-8671.2015.1.12586. URL: http://www.e-notabene.ru/wi/article_12586.html

21. Karyakin V.V. Tsivilizatsionnaya antropologiya amerikanskogo ekspansionizma: ot doktriny Monro k global'nomu liderstvu // Mezhdunarodnye otnosheniya. - 2013. - 4. - C. 487 - 468. DOI: 10.7256/2305-560X.2013.4.9722.

22. Fel'dman P.Ya. Geopoliticheskii klientelizm v mezhdunarodnykh otnosheniyakh: strategiya i taktika Zapada. // Mezhdunarodnye otnosheniya. - 2014. - 2. - C. 189 - 193. DOI: 10.7256/2305-560X.2014.2.11365.

23. Semchenkov A.S. Voennye ugrozy bezopasnosti gosudarstv v usloviyakh globalizatsii // Konfliktologiya / nota bene. - 2015. - 3. - C. 292 - 304. DOI: 10.7256/2409-8965.2015.3.14334.

24. Gusher A.I. Krizis na Ukraine: geopoliticheskie i geostrategicheskie aspekty // Mirovaya politika. - 2014. - 4. - C. 79 - 89. DOI: 10.7256/2409-8671.2014.4.11605. URL: http://www.e-notabene.ru/wi/article_11605.html

25. Saushkin A. Perspektivy otmeny sanktsii v otnoshenii Rossii // Mezhdunarodnye otnosheniya. - 2015. - 1. - C. 117 - 120. DOI: 10.7256/2305-560X.2015.1.13506.

26. Gusher A.I. Ekspertnaya otsenka politiko-ekonomicheskoi situatsii v Ukraine // Mezhdunarodnye otnosheniya. - 2014. - 3. - C. 326 - 331. DOI: 10.7256/2305-560X.2014.3.11815.

27. Bunevich D.S. Krymskii krizis 2014 goda i sozdanie novoi arkhitektury mezhdunarodnykh otnoshenii // Konfliktologiya / nota bene. - 2015. - 2. - C. 133 - 139. DOI: 10.7256/2409-8965.2015.2.14333.

28. A. E. Galumov Rol' publichnoi diplomatii v formirovanii pozitivnogo imidzha ES v Rossii // Natsional'naya bezopasnost' / nota bene. - 2012. - 4. - C. 77 - 85.

29. Fedyakin I.V. Megapolisy kak sub"ekty politiki: istoriya i sovremennoe sostoyanie // Mezhdunarodnye otnosheniya. - 2014. - 1. - C. 88 - 93. DOI: 10.7256/2305-560X.2014.1.10165. 